\title{
Two Cases in which Enlarged Wandering Spleens simulated Pelvic Neoplasms.
}

\author{
By Frani E. Taylor, M.B., B.S. (Lond.), F.R.C.S. (Eng.), \\ Pathologist to the Chelsea Hospital for Women, London.
}

That an enlarged spleen, when forming an abdominal, or even an abdomino-pelvic swelling, may simulate a solid or cystic uterine or ovarian tumour is a well-recognised fact. Indeed, most text-books on gynecology mention this as one of the conditions to be taken into consideration in arriving at a differential diagnosis of these diseases.

Lieut.-col. Sturmer, ${ }^{1}$ of Madras, has described a case of this nature in this Jocrnal for October, 1904. As an indication of the rarety of any real difficulty arising in this connection he states that "up to the present $I$ never had any difficulty in diagnosing an enlargement of the spleen, and I must have seen hundreds of cases-for India is the land of the enlarged spleen." He therefore considers that such cases "seem worthy of record, if only to put others on their guard, and to prevent them from mistaking an enlarged spleen from some growth arising out of the pelvis."

The characteristic features of a splenic enlargement which should differentiate it from pelvic and abdominal neoplasms are, according to Sturmer, as follows:-

1. The growth can be traced to its origin under the ribs.

2. There is usually a well-marked history of fever.

3. Cachexia is generally present.

4. The presence of a "notch" in the border of the tumour. None of these guides, however, was available in the following cases; consequently the splenic enlargement was in each case mistaken for an ovarian tumour.

Similar cases have also been recorded by Ashby, ${ }^{2}$ Gray Croly, ${ }^{3}$ Pozzi, Bland-Sutton, ${ }^{5}$ Richelot, ${ }^{6}$ and others.

Two cases are on record-those of Dietl ${ }^{7}$ and Rezel ${ }^{8}$-in which the enlarged spleen was even considered to be the pregnant uterus.

CASE I. * E.B., a married woman, aged 32, was admitted into Chelsea Hospital for Women, under the care of Dr. W. H. Fenton, on January 1st, 1904, complaining of pain in the left side, accompanied by sickness and diarrhoea. She had had two children, the last fifteen months prior to admission into hospital. At this confinement

- Shown at Obstet Soc., London, May, 1904. 
she was kept in bed for six weeks on account of "septic fever." Whilst then lying in bed she first noticed a lump in the right iliac region, and she experienced a good deal of pain in the same situation.

In September, 1903, she attended as an out-patient, and was then found to have a hard mass in the right iliac region, extending inwards as far as the middle line of the abdomen, and upwards as far as the umbilicus. She was recommended to become an in-patient but refused to do so. From this time until admission in January last, she has had a good deal of sickness and diarrhoea, having had two very severe attacks on Christmas Eve, and on New Year's Eve, and these she called "bilious attacks."

The catamenia were regular, lasting - seven days out of every twenty-eight, and the loss was fairly profuse, and unaccompanied by pain or clots. Between the periods there was some creamy-white vaginal discharge. Micturition was normal throughout.

On physical examination the heart and lungs were found to be normal. The surface of the abdomen was dark in colour, and there was some intestinal distension in the umbilical region. Below the level of the umbilicus, and chiefly on the right side, but also extending across the middle line towards the left, was a hard, firm mass, rising up in the right flank almost to the level of the umbilicus. It was extremely tender on deep palpation. Its surface was smooth and uniform. It presented a well-defined edge, in which no notch could be felt, neither could any movement be elicited.

Per vaginam a hard mass was felt to occupy the anterior fornix; it also extended to the left, forming a very large tumour; it was very tender, and only very slight movement could be induced. The uterus occupied the pouch of Douglas behind the tumour, with which it had no connection.

The history of the case, the apparent origin of the swelling during a septic puerperium, and the presence of a hard mass in the pelvis suggested the diagnosis of parametritis. The definiteness of the swelling and the presence of slight mobility entirely negatived this view. The fact that the tumour occupied the pelvis and was free from the uterus caused it to be diagnosed as an ovarian tumour. The patient's general condition was so bad that operation was deferred until February 19th. In the interval she was kept in bed, and with skilful nursing and appropriate treatment she improved very considerably.

On February 19th, Dr. Fenton opened the abdomen through a sub-umbilical median incision, and found the tumour to be an enlarged spleen embedded in the right side of the pelvis and extend- 
ing up into the right iliac region. After separating the adhesions, the pedicle of the spleen was found to be twisted through two-and-ahalf complete turns. The tail of the pancreas was contained in the pedicle, and extended to within two inches of the spleen. The portion of the pedicle intervening between the tip of the tail of the pancreas and the spleen, was ligatured by transfixion and cut through, the spleen being thus removed. The abdominal wound was sewn up in three layers. Except that for a couple of days after operation the patient was somewhat restless, recovery was uneventful, the temperature never reaching beyond $99 \cdot 8^{\circ} \mathrm{F}$., and only touching this figure once on the day following operation. The wound healed per primam throughout, and the stitches were removed on the eighth day. The patient left the hospital perfectly well on March 10th, that is twenty days after the splenectomy.

Examination of the specimen removed showed it to be a uniformly enlarged spleen measuring $8 \frac{1}{2}$ inches in length, $5 \frac{1}{2}$ inches in breadth, and 3 inches in thickness. It weighed 41 ounces. It was softish and elastic in consistence and dark purple in colour. Its peritoneal surface was smooth or glistening and free from adhesions. It was hardened whole in formalin. On being bisected it presented a striking appearance. The whole of the central part of the tumour, forming the major portion of it, was seen to be composed of a large hæmorrhagic mass, bright red in colour. Round this a thin layer of splenic tissue of a dark-brown hue was spread out, with larger accumulations at each end. The capsule of the spleen is also thickened.

The changes observed on microscopic examination are the presence of a large central hæmorrhagic mass in which no trace of splenic tissue is discernible, which is surrounded by splenic tissue, with increased trabecular connective tissue and thickening of the connective tissue capsule.

CASE II.* S.B., married, aged 29, was admitted into Chelsea Hospital for Women under the care of Dr. Victor Bonney on Sept. 18th, 1904, complaining of a more or less constant dull, aching pain, in the left side, in the back, and in the legs. This had been present on and off for several years and had several times caused her to seek medical advice; it was always considered to be, and was treated as, indigestion and flatulence. The patient had never had any children or miscarriages, but had only been married six months. Menstruation was always regular until the last period, which appeared ón Aug.28th, 
a fortnight earlier than usual, and was very profuse, several small clots being passed. It lasted fifteen days, and was accompanied by great pain, so that on the first day of the period the patient had to lie in bed. There was also marked constipation.

On admission a systolic bruit was heard at the apex. The lungs were normal. There was some resistance and tenderness on palpation in the left iliac fossa; otherwise abdominal examination was negative.

Per vaginam the cervix was felt low down and forward, the uterus being retroverted. It was also tender and slightly enlarged. In the left lateral and anterior fornices a softish tumour about the size of a hen's egg could be felt. It was tender on pressure.

On September 20th these findings were confirmed by examination under an anæsthetic, and the swelling was diagnosed as a cystic tumour of the left ovary, lying in front of and causing retroversion of the uterus.

On September 27th Dr. Bonney opened the abdomen in the middle line below the umbilicus. The enlarged spleen was found in the left side of the pelvis in front of the body of the uterus, which was lying retroverted. The pedicle of the spleen was slightly twisted. This was transfixed by a silk ligature and the spleen was then removed. There were some adhesions round the left ovary and tube; these were broken down. The uterus was freed and lifted up into position. The right appendages appeared to be quite healthy. Recovery was rapid and uneventful and patient left the hospital quite well on October 13th, 1904.

The spleen, after removal, measured along its convexity 61 in. $\times 3$ in.; it weighed 8 ounces. Its peritoneal surface was rough and ragged from peri-splenitis. The notch was peculiarly situated near one end of the organ, and was so deep that it almost entirely cut off that end of the spleen. Had the notch extended a little deeper a portion of the spleen would have been completely detached and would then have formed an accessory spleen. Section of the spleen showed it to be composed of normal splenic tissue.

Cases of this description, that is to say, cases in which the displaced spleen rests upon the body of the uterus and by its superincumbent weight brings about a retro-displacement of that organ, are very few in number, the only cases of which $I$ have been able to find any record being those of Bland-Sutton, ${ }^{9}$ Clarence Webster, ${ }^{10}$ Runge, ${ }^{11}$ and Plücker. ${ }^{12}$ A still more unusual case is that of Klein, ${ }^{13}$ in which the pelvic spleen was considered to be the retroflexed fundus of the uterus, and had accordingly been treated with a ring pessary. 
It is unfortunate that in neither of these cases was any blood examination undertaken, as this would probably have thrown some light upon the nature of the splenic enlargement. Nevertheless, there seems little doubt that in the first case, as the specimen shows, the enlargement of the spleen was due to the hæmorrhage caused by the torsion of the pedicle. It is possible that the attacks of pain and sickness which the patient described as "bilious attacks" were in reality caused by distinct and separate hæmorrhages into the spleen.

In the second case, neither the clinical history nor the appearance of the spleen itself suggests any factor of ætiological significance, either as to the enlargement or the displacement of the spleen. The perisplenitis, as evidenced by the thickened and ragged state of the capsule, was probably a secondary phenomenon which arose whilst the enlarged spleen occupied its acquired position in the pelvis.

Finally it is my pleasant duty to place on record my thanks to Dr. Fenton and Dr. Bonney, for their kindness in allowing me to publish these cases.

\section{REFERENCES.}

1. Sturmer. "Enlargement of the Spleen Simulating a Pelvic Growth: Splenectomy." Journ. of Obstet. and Gyn. of Brit. Empire, Octaber, 1904.

2. Ashby. "Report of a Case of Splenectomy for Wandering Spleen, Complicated with Typhoid Fever ; Recovery." Amer. Gynecology, 1902. Vol. i., p. 175.

3. Gray Croly. "Misplaced and Rotated Spleen which Simulated an Ovarian Tumour." Trans. Roy. Acad. of Med., Ireland, 1896. Vol. xiv., p. 262.

4. Poxzi. "Displacement of the Spleen with Excessive Elongation, Torsion and Rupture of the Pedicle, following Malarial Splenomegaly : Splenectomy : Cure." Bulletin et Mém. de la Soc. de Chir. de Paris, August, 1903, p. 867.

5. Bland-Sutton. "A Case of Axial Rotation of a Wandering Spleen: Splenectomy; Recovery." Trans. Clin. Soc., London, 1896. Vol. rxvi., p. 46.

6. Richelot. Le Progrés Medical, 1903, p. 456.

7. Dietl. Wien. med. Wochenschr., 1854. Nos. 19 and 20.

8. Rezel. Wien. med. Wochenschr, 1856. No. 27.

9. Bland-Sutton. "A Case in which Splenectomy was performed for a Wandering Spleen." Trans. Clin. Soc., London, 1901. Vol. xxxiv., p. 31.

10. Clarence Webster. "A Case of Successful Removal of an Enlarged Spleen with Twisted Pedicle, Adherent to the Right Side of the Pelvis, etc." Journ. of Amer. Med. A8soc. Vol. xl., p. 887.

11. Runge. "Extirpatio einer Wandermilz mit Axendrehung des Stieles." Berlin klin. Wochenschr, 1895. No. 16.

12. Plücker. "Uber Splenopexis bei Wandermily." Centr. f. Chirurg., 1895. No. 40.

13. Klein. Münch. med. Wochensehr, 1889, p. 751. 